\title{
KAJIAN STRUKTUR INDUSTRI PERIKANAN UNTUK MENYUSUN MODEL PEMBERDAYAAN USAHA PERIKANAN TANGKAP DI DAERAH ISTIMEWA YOGYAKARTA ${ }^{1}$.
}

\author{
Mulyono Partosuwirjo², \\ John Haluan, Mulyono S. Baskoro dan Soepanto Soemokaryo
}

\begin{abstract}
ABSTRAK
Usaha perikanan tangkap berperan penting dalam kegiatan ekonomi dan kehidupan masyarakat di Daerah Istimewa Yogyakarta, namun dinamika interaksi di antara komponen perikanan belum harmonis karena penanganan permasalahannya belum sesuai dengan intensitas interaksi. Penelitian ini bertujuan menganalisis dan mengidentifikasi komponen/aspek yang berinteraksi signifikan sehingga dapat diantisipasi untuk penyusunan model pemberdayaan usaha perikanan tangkap yang lebih tepat. Penelitian ini dilakukan melalui analisis interaksi kompleks menggunakan Structure Equation Modelling (SEM). Hasil analisis SEM menerangkan bahwa komponen lingkungan internal, lingkungan eksternal, dan lingkungan industri, strategi usaha, kinerja industri perikanan, dan tujuan pembangunan perikanan berinteraksi signifikan berturut-turut dengan aspek manajemen, sosial, entry barier, keuangan, pay back period. Pada lingkup interaksi lebih tinggi, Lingkungan Internal berinteraksi positif signifikan dominan terhadap Lingkungan Eksternal. Lingkungan Eksternal berpengaruh positif signifikan dominan terhadap Lingkungan Industri. Sedangkan Strategi Usaha berpengaruh positif signifikan dominan terhadap Tujuan Pembangunan Perikanan. Dalam kaitan ini, maka berbagai permasalahan menyangkut komponen yang berinteraksi signifikan tersebut harus diprioritaskan karena bila tidak akan dapat secara serius mengganggu aktivitas perikanan tangkap yang ada di Daerah Istimewa Yogyakarta.
\end{abstract}

Kata Kunci :Interaksi, SEM, Signifikan, Perikanan Tangkap, Yokyakarta.

\section{Abstract :Assessment of Fisheries Industrial Structure to Develop an Empowerment Model of the Capture Fisheries Business in Yogyakarta. By: Mulyono Partosuwirjo,John Haluan, Mulyono S. Baskoro dan Soepanto Soemokaryo.}

Capture fishery has an important role in the economic activity and livelihood among the people of Yogyakarta. However, the dynamic interactions among the components of fisheries have yet harmonised because problem solving had yet in accordance to interaction intensity. This research aimed to analyse and identify some components having significant interaction so that they can be used to anticipate in developing appropriate model for empowering capture fishery business. This research was conducted through analysis of complex interaction with Structure Equation Modelling (SEM). Results of the SEM analysis showed that the environments (internal, external, and industrial), business strategies, fishing industry performance, and development goals had a significant interaction respectivelly with management, social aspect, entry barrier, finance, and pay back period. For higher interaction scope, internal environment has a significant positive dominancy to the external environment. External environment had a significant positive dominancy to the industrial environment. While business strategies had a significant positive effect on the goal of fisheries development. In these respect, various problems related to component that significantly interacted has to be prioritised. This is because it directly leads to disturb the capture fishery activity in Yogyakarta.

Keywords: Interaction, SEM, Significancy, Capture Fishery and Yogyakarta.

\footnotetext{
${ }^{1}$ Bagian dari Disertasi dengan judul' Pemberdayaan Usaha Perikanan Tangkap di Daerah Istimewa Yogyakarta'

2 Mahasiswa Program Studi Teknologi Kelautan Pascasarjana IPB Bogor

${ }^{3}$ Dosen Program Pasca Sarjana Teknologi Kelautan, IPB Bogor
} 


\section{PENDAHULUAN}

Propinsi Daerah Istimewa Yogyakarta mempunyai potensi sumberdaya perikanan laut yang cukup besar sehingga mempunyai peluang yang cukup besar untuk pengembangan usaha perikanan tangkap. Potensi tersebut meliputi perairan laut dengan panjang pantai $\pm 110 \mathrm{~km}$ dengan daerah operasi penangkapan 12 mil dari pantai. Nilai produksi perairan mencapai sebesar 905,3 ribu ton/tahun. Namun potensi yang cukup besar tersebut masih diusahakan oleh rakyat menggunakan armada penangkapan skala kecil dan dan beberapa tidak layak untuk lokasi.

Selama ini, usaha perikanan tangkap di Propinsi Daerah Istimewa Yogyakarta tidak hanya sebagai penyedia pangan, bahan baku industri dan ekspor, tetapi juga sekaligus menjadi tempat sandaran kehidupan bagi sebagian masyarakat sekitar pantai. Keadaan ini telah menumbuhkan berbagai pemikiran tentang pemberdayaan nelayan dengan meningkatkan posisi tawar mereka melalui penataan kelembagaan usaha, kelembagaan pasar, dan kelembagaan pelayanan. Namun hal ini belum berjalan dengan baik karena dinamika interaksi usaha perikanan tangkap belum efektif dan masih didominasi oleh praktek monopoli. Pola interaksi diantara komponen dan stakeholders perlu diarahkan sehingga mendukung peran yang diemban usaha perikanan tangkap tersebut.

Banyak bantuan pemerintah kepada usaha perikanan (nelayan) yang kurang tepat sasaran. Hal ini terlihat dari pertumbuhan usaha dan industri perikanan masih rendah (di bawah 2 \%) meskipun sudah mendapat pembinaan dari aparat Pemerintah. Terkait dengan ini, maka penulis melakukan penelitian ini untuk mengetahui hal tersebut secara kuantitatif melalui analisis interaksi komponen terkait lingkungan industri perikanan sehingga dapat membantu memilih komponen/aspek yang harus diprioritaskan untuk memberdayakan usaha perikanan tangkap secara tepat.
Tujuan penelitian ini adalah menganalisis dan mengidentifikasi komponon/aspek yang berinteraksi secara signifikan di lingkungan industri perikanan sehingga dapat diantisipasi untuk penyusunan model pemberdayaan usaha perikanan tangkap yang lebih tepat di Daerah Istimewa Yogyakarta.

\section{METODOLOGI}

\section{Waktu dan Lokasi Penelitian}

Penelitian ini dilakukan di Propinsi Daerah Istimewa Yogyakarta (DIY) khususnya daerah pantai yang potensial dan diandalkan usaha perikanannya seperti Sadeng, Glagah, Depok, dan Baron. Lokasi tersebut terandalkan karena menjadi penyumbang lebih dari $80 \%$ produksi ikan DIY. Penelitian dilakukan mulai bulan Januari tahun 2006 sampai dengan bulan Juni tahun 2007.

\section{Jenis Data yang Dikumpulkan}

Jenis data yang dikumpulkan dalam penelitian ini terdiri dari data primer dan data sekunder. Data primer merupakan data yang langsung dikumpulkan di lapangan terkait industri perikanan tangkap. Data sekunder merupakan data yang sudah tersedia yang mendukung kelengkapan data penelitian. Jenis data yang dikumpulkan; data manajemen, ekonomi, keuangan, sosial, politik, teknologi dan lain-lain yang ada relevansinya.

\section{Metode Pengumpulan Data Metode Pengumpulan Data Primer}

Metode pengumpulan data primer terdiri dari pemilihan kelompok sampling, identifikasi responden, dan pengumpulan data responden. Disamping data responden, data primer berupa data pengamatan langsung tentang kondisi perikanan tangkap di lapang.

\section{Metode Pengumpulan Data Sekunder}

Metode pengumpulan data sekunder terdiri dari studi kasus dan literatur, pendapat pakar, dan kombinasi ketiganya. 


\section{Metode Analisis}

Untuk mengembangkan analisis interaksi ini digunakan Structural Equation Modelling( SEM). SEM merupakan metode analisis interaksi kompleks diantara beberapa komponen yang terlibat dalam suatu sistem nyata. Dalam analisis SEM, komponenkomponen tersebut diformat secara struktural ke dalam konstruk atau dimensi konstruk sehingga dapat diinteraksikan secara bebas seperti sebenarnya di alam. Adapun tahapan yang dilakukan dalam analisis interaksi lingkungan industri menggunakan SEM adalah:

\section{Pengembangan model teoritis}

Pengembangan model teroritis dimaksudkan untuk mendapatkan justifikasi terhadap konsep-konsep yang dikembangkan sehingga dapat dipertanggungjawabkan dan mendapat kebenaran secara ilmiah. Dalam kaitan ini, telaah pustaka, eksplorasi terhadap hasil-hasil penelitian yang berkaitan, dan diskusi pakar menjadi hal penting untuk dilakukan.

\section{Pembuatan diagram alur}

Pembuatan path diagram merupakan kegiatan penggambaran interaksi komponenkomponen yang dikembangkan secara teoritis yang kemudian menjadi konstruk penelitian.

\section{Perumusan measurement model dan structural equation}

Tahapan ini merupakan perumusan path diagram ke dalam persamaan matematis, sehingga dapat digunakan untuk analisis SEM. Persamaan tersebut terdiri dari persamaan pengukuran (measurement model) dan persamaan struktur (structural equation). Measurement model merupakan kegiatan merumuskan interaksi antara dimensi konstruk (parameter) dengan konstruk, dan structural equation merupakan kegiatan merumuskan interaksi antara konstruk dengan konstruk lainnya.

\section{Pemilihan matriks input dan estimasi model}

Teknik estimasi tersebut dapat dipilih sesuai dengan ukuran sampel. Oleh karena dalam penelitian ini digunakan 150 sampel, maka teknik estimasi yang digunakan matriks likelihood estimation (MLE). MLE mensyaratkan ukuran sampel berkisar 100-200 sampel.

\section{Evaluasi kriteria goodness-of-fit}

Tahapan merupakan kegiatan mengevaluasi kesesuaian model yang dibuat menggunakan berbagai kriteria goodness-offit, yaitu $X^{2}$-Chi-square diharapkan kecil, significance probability $>0,05$, RMSEA $<0,08$, GFI > 0,90, AGFI > 0,90, CMIN/DF < 2,00, TLI $>0,95$, dan CFI > 0,95 (Ferdinand, 2002).

\section{Analisis pengaruh (effect analysis)}

Effect analysis dilakukan terhadap model yang dibangun yang telah diuji kesesuaiannya dan dievaluasi secara statistik dan telah dinyatakan layak atau diterima.

\section{HASIL DAN PEMBAHASAN}

\section{Model Pengembangan Industri Perikanan Dengan Interaksi Sederhana Komponen Terkait}

\section{Aspek Teoritis Pengembangan Model}

Model pengembangan industri perikanan ini dilakukan dengan memadukan interaksi berbagai komponen terkait dalam pengembangan industri perikanan secara umum. Hasil kajian teoritis menunjukkan bahwa beberapa komponen yang terkait dengan pengembangan industri perikanan adalah lingkungan internal (LINT), lingkungan eksternal (LEX), lingkungan industri (LIN), strategi usaha (STRG), kinerja organisasi (UPT), dan Tujuan Pembangunan Perikanan (TPP).

Interaksi terkait Lingkungan Internal (LINT) Berdasarkan hasil analisis Tabel 1, Lingkungan Internal (LINT) berpengaruh 
positif signifikan terhadap Teknologi (X11), Pesaing (X12), Manajemen (X13), dan Sumberdaya Manusia (X16). Oleh karena signifikan, maka teknologi (X11), administrasi (X12), dan sumberdaya manusia (X16) menjadi indikator penting menentukan maju mundurnya kegiatan perikanan tangkap di Daerah Istimewa Yogyakarta. Modal (X14) dan Sarana (X15) merupakan dimensi konstruk yang tidak dipengaruhi secara signifikan karena mempunyai nilai $p>0,05$ meskipun koefisien interaksi masing-masing 0,067 dan 0,066 . positif signifikan terhadap konstruk Lingkup Usaha Perikanan tangkap (LUP) sebesar 0,09 dengan nilai $p=0,029$. Terkait dengan ini, maka Lingkup Industri Perikanan (LIP) menjadi faktor yang berpotensi serius mempengaruhi aktivitas dan kondisi internal usaha perikanan tangkap di Daerah Istimewa Yogyakarta. Hal ini terjadi karena lingkup usaha menentukan jenis dan skala usaha perikanan tangkap yang dapat dilakukan oleh nelayan sehingga secara langsung maupun tidak langsung dapat mempengaruhi kondisi internal usaha perikanan tangkap yang ada.

Tabel 1. Koefisien Pengaruh dan Significance of Dimensi Probability Dimensi Konstruk yang Berinteraksi dengan Konstruk Lingkungan Internal (LINT).

Table 1. Coeficient of Effect and Significance of Probability Construct Dimension Interated with Internal Environment Construct (LINT).

\begin{tabular}{llccc}
\hline Konstruk /Construct & $\begin{array}{l}\text { Dimensi Konstruk Indikator/ } \\
\text { Endicator of Construct } \\
\text { Dimension }\end{array}$ & $\begin{array}{l}\text { Koefisien } \\
\text { Pengaruh/ } \\
\text { Coeficient of } \\
\text { Impact }\end{array}$ & $\mathrm{P}$ & $\mathrm{S} / \mathrm{TS}$ \\
\hline Lingkungan Internal & Teknologi (X11)/Technology & 0,152 & 0,011 & $\mathrm{~S}$ \\
(LINT)/ & Administrasi(X12)/Administration & 0,119 & 0,021 & $\mathrm{~S}$ \\
Internal Environment & Manajemen (X13)/Management & 1,000 & 0,040 & $\mathrm{~S}$ \\
& Modal (X14)/Capital & 0,261 & 0,067 & $\mathrm{TS}$ \\
& Sarana (X15)/Infrastructure & 0,066 & 0,104 & TS \\
& Sumberdaya manusia & 0,031 & 0,022 & $\mathrm{~S}$ \\
\hline
\end{tabular}

Sumber : Hasil Olahan SEM (2007)/Source :SEM Analysis (2007).

Keterangan/Remarks : $p=$ Nilai Significance of Probability/Significance of Probability.

$\mathrm{S}=$ Pengaruh Signifikan/Significanthy Affected .

TS = Pengaruh tidak Signifikan/Unsignificanthy Affected.

Untuk lima dimensi konstruk yang dipengaruhi signifikan tersebut, manajemen (X13) merupakan dipengaruhi paling dominan. Hal ini mengindikasikan bahwa manajemen merupakan aspek internal paling sensitif mengganggu kondisi internal industri perikanan. Terkait dengan ini, maka manajemen pengelolaan usaha perikanan tangkap harus segera dibenahi dalam upaya pemberdayaan industri perikanan di Daerah Istimewa Yogyakarta. Dilain pihak, untuk pengaruhnya terhadap konstruk, konstruk Lingkungan Internal (LINT) berpengaruh

\section{Interaksi terkait Lingkungan Eksternal (LEX)}

Berdasarkan hasil analisis SEM, interaksi Lingkungan Eksternal (LEXT) dengan Politik (X21), Ekonomi (X22) mempunyai probanilitas $<0,05$. Terkait dengan ini, maka Lingkungan Eksternal (LEXT) berpengaruh/berinteraksi positif signifikan terhadap ketiga dimensi konstruk tersebut. Hal ini menunjukkan aspek Politik (X21), Ekonomi (X22), dan Sosial (X23) berpotensi serius secara eksternal mengganggu kegiatan perikanan tangkap di Daerah Istimewa Yogyakarta. 
Dari ketiga dimensi konstruk tersebut, Sosial (X23) merupakan dimensi konstruk yang dipengaruhi paling dominan oleh Lingkungan Eksternal (LEX). Pengaruh terhadap aspek sosial dapat dikarenakan oleh sensitifnya masalah-masalah sosial (seperti kesenjangan penghasilan, kesempatan kerja, pendidikan) sehingga mudah menggangu industri/usaha perikanan tangkap dari segi eksternal di Daerah Istimewa Yogyakarta.

Disamping itu, Lingkungan Eksternal (LEX) berpengaruh positif terhadap konstruk Lingkungan Industri Perikanan (LIN) dengan koefisien pengaruh 0,097 dengan nilai $\mathrm{p}=$ 0,048 . Oleh karena probabilitasnya $<0,05$, maka pengaruh positif tersebut bersifat signifikan.

\section{Interaksi terkait Lingkungan Industri (LIN)}

Berdasarkan hasil analisis SEM, Lingkungan Industri (LIN) dalam pengembangan industri perikanan di Daerah Istimewa Yogyakarta mempengaruhi Entry barrier(X31), Pesaing (X32), dan Supply (X33). Pengaruh Lingkungan Industri (LIN) terhadap ketiga dimensi konstruk menunjukkan entry barrier (X31), pesaing (X32), dan supply (X33) dipengaruhi secara positif signifikan karena mempunyai nilai probabalitas $<0,05$. Dalam kaitan ini, maka entry barrier (X31), pesaing (X32), dan supply (X33) berpotensi serius menganggu kegiatan perikanan tangkap di Daerah Istimewa Yogyakarta.

Entry barrier (X31) merupakan dimensi konstruk yang dipengaruhi paling dominan diantara tiga dimensi konstruk tersebut. Hal ini mengindikasikan order dan arus barang masuk merupakan faktor paling penting diperhitungkan bila industri perikanan dikembangkan. Disamping itu, Lingkungan

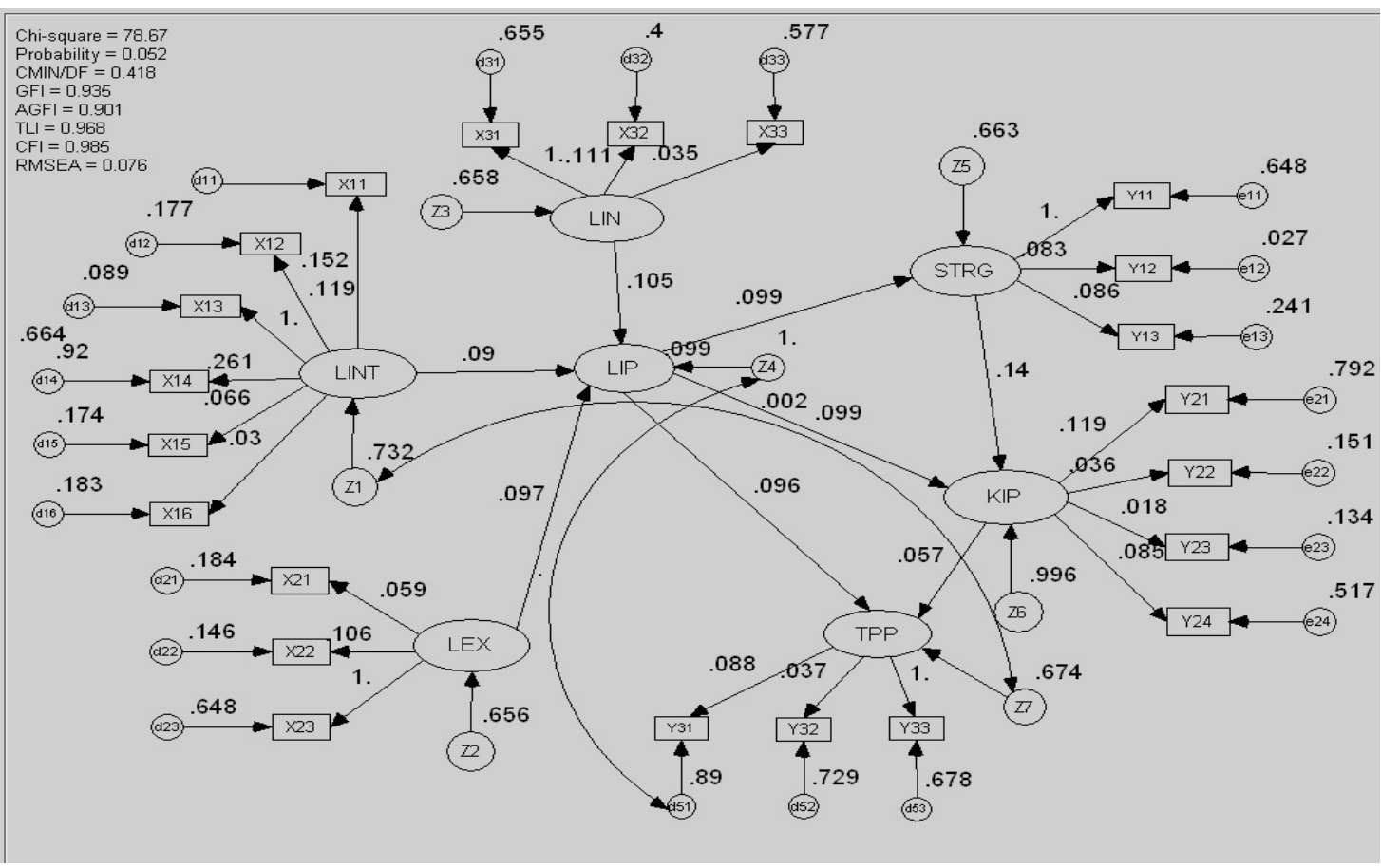

Gambar 1. Model Pengembangan Industri Perikanan dengan Interaksi Sederhana Komponen Terkait.

Figure 1. Model of Fisheries Industrial Development by Simple Interaction of Related Components. 
Industri (LIN) juga berinteraksi dengan konstruk yaitu Lingkup Usaha Perikanan Tangkap (LUP) yang dipengaruhi secara positif signifikan dengan koefisien pengaruh 0,105 dan nilai probabilitas 0,067 .

\section{Interaksi Terkait Lingkup Industri Perikanan (LIP)}

Berdasarkan Tabel 3., Lingkup Industri Perikanan (LIP) berpengaruh positif terhadap Strategi Usaha (STRG) dengan nilai koefisien pengaruh 0,099 dan probabilitas 0,042, berpengaruh positif terhadap konstruk Kinerja Industri Perikanan (KIP) dengan nilai koefisien pengaruh 0,099 dan probabilitas 0,101, berpengaruh positif terhadap Tujuan Pembangunan Perikanan (TPP) dengan koefisien pengaruh 0,096 dan probabilitas 0,027 . Terkait dengan ini, maka Strategi Usaha (STRG) dan Tujuan Pembangunan Perikanan (TPP) menjadi faktor yang berpotensi serius mempengaruhi jenis dan skala usaha perikanan di Daerah Istimewa
Yogyakarta, sedangkan Kinerja Usaha Perikanan (KIP) tidak menjadi indikator penting karena probabilitas $>0,05$.

Dari dua konstruk yang berinteraksi signifikan dengan Lingkup Industri Perikanan (LIP), pengaruh terhadap Strategi Usaha (STRG) sedikit lebih dominan. Terkait dengan ini, maka pengembangan industri perikanan di Daerah Istimewa Yogyakarta harus mengakomodir kondisi tersebut.

\section{Interaksi Terkait Strategi Usaha (STRG)}

Strategi usaha (STRG) merupakan hal penting dalam penentuan berbagai upaya untuk pengembangan industri perikanan. Strategi yang diambil dalam suatu usaha biasanya berkaitan dengan kondisi produksi, pemasaran, dan keuangan yang dapat dilakukan. Berdasarkan hasil analisis SEM, Strategi Usaha (STRG) berpengaruh positif tidak signifikan sebesar 1,000 dengan nilai $p=$ 0,245 terhadap Produksi (Y11), berpengaruh positif signifikan sebesar 0,082 dengan nilai $p$ $=0,044$ terhadap Pemasaran (Y12), dan

Tabel 2. Koefisien Pengaruh dan Significance of Probability Konstruk yang Berinteraksi dengan Konstruk Lingkup Industri Perikanan (LIP).

Table 2. Coeficient of Effect and Significance of Probability Construct Dimension Interated with Fisheries Industres Construct.

\begin{tabular}{|c|c|c|c|c|}
\hline Konstruk /Construct & $\begin{array}{l}\text { Konstruk Indikator/ } \\
\text { Indicator of Construct }\end{array}$ & $\begin{array}{l}\text { Koefisien } \\
\text { Pengaruh/ } \\
\text { Coeficient of } \\
\text { Impact }\end{array}$ & $P$ & S/TS \\
\hline \multirow{3}{*}{$\begin{array}{l}\text { Lingkup Industri Perikanan } \\
\text { (LIP)/ Fisheries Industrial } \\
\text { Scope }\end{array}$} & $\begin{array}{l}\text { Strategi Usaha (STRG)/ } \\
\text { Business Strategy }\end{array}$ & 0,099 & 0,042 & S \\
\hline & $\begin{array}{l}\text { Kebijakan Indutri } \\
\text { Perikanan (KIP)/ } \\
\text { Policy of Fisheries } \\
\text { Industry }\end{array}$ & 0,099 & 0,101 & TS \\
\hline & $\begin{array}{l}\text { Tujuan Pembangunan } \\
\text { Perikanan (TPP)/ } \\
\text { Fisheries Development } \\
\text { Goals }\end{array}$ & 0,096 & 0,027 & S \\
\hline
\end{tabular}

Sumber : Hasil Olahan SEM (2007)/Source :SEM Analysis (2007).

Keterangan/Remarks: $p=$ Nilai Significance of Probability/Significance of Probability.

$S=$ Pengaruh Signifikan/Significanthy Affected. .

TS = Pengaruh tidak Signifikan/Unsignificanthy Affected . 
Tabel 3. Koefisien Pengaruh dan Significance of Probability Konstruk/Dimensi Konstruk yang Berinteraksi dengan Konstruk Strategi Usaha (STRG).

Table 3. Coeficient of Effect and Significance of Probability of Construct /Dimension Interacted with Business Strategy Construct.

\begin{tabular}{llccc}
\hline Konstruk /Construct & $\begin{array}{c}\text { Dimensi Konstruk Indikator/ } \\
\text { Endicator of Construct } \\
\text { Dimension }\end{array}$ & $\begin{array}{c}\text { Koefisien } \\
\text { Pengaruh/ } \\
\text { Coeficient of } \\
\text { Impact }\end{array}$ & $\mathrm{P}$ & $\mathrm{S} / \mathrm{TS}$ \\
\hline $\begin{array}{l}\text { Strategi usaha } \\
\text { (STRG)/ Business } \\
\text { Strategy }\end{array}$ & Produksi (Y11)/ Production & 1,000 & 0,245 & $\mathrm{TS}$ \\
& pemasaran (Y12)/ Marketing & 0,082 & 0,044 & $\mathrm{~S}$ \\
& Keuangan (Y13)/ Finance & 0,086 & 0,000 & $\mathrm{~S}$ \\
\hline
\end{tabular}

Sumber : Hasil Olahan SEM (2007)/Source :SEM Analysis (2007).

Keterangan/Remarks : $p=$ Nilai Significance of Probability/Significance of Probability.

$\mathrm{S}=$ Pengaruh Signifikan/Significanthy Affected .

TS = Pengaruh tidak Signifikan/Unsignificanthy Affected.

Terkait dengan ini, maka aspek Produksi (Y11) tidak dianggap faktor penting untuk diperhitungkan dalam penentuan strategi usaha perikanan. Sedangkan aspek Pemasaran (Y12) dan Keuangan (Y13) menjadi faktor yang berpotensi serius mempengaruhi strategi usaha perikanan di Daerah Istimewa Yogyakarta. Oleh karena itu, kondisi pemasaran usaha maupun kondisi keuangan usaha harus menjadi titik berat dalam pengembangan keputusan strategi usaha perikanan tangkap yang dikembangkan di masa datang.

Disamping interaksi dengan dimensi konstruk, Strategi Usaha (STRG) juga berinteraksi dengan konstruk Kinerja Industri Perikanan (KIP) secara positif signifikan dengan koefisien pengaruh 0,14 dengan nilai $p$ $=0,035$. Terkait dengan ini, maka Kinerja Industri Perikanan (KIP) termasuk faktor serius mempengaruhi strategi usaha perikanan di Daerah Istimewa Yogyakarta. Hal ini dikarenakan arah pengembangan suatu usaha biasanya ditentukan oleh progress atau kinerja dari usaha tersebut selama ini.

\section{Kinerja Industri Perikanan (KIP)}

Berdasarkan hasil analisis SEM, konstruk Kinerja Industri Perikanan (KIP) mempengaruhi secara positif siginifikan dimensi konstruk pay back Period (Y21) sebesar 0,0119 dengan nilai $p=0,002$, mempengaruhi secara positif tidak signifikan dimensi konstruk Rugi/Laba (Y22) sebesar 0,036 dengan nilai $p=0,327$, mempengaruhi secara positif signifikan dimensi konstruk Return of Investment (Y23) sebesar 0,018 dengan nilai $p=0,001$, dan mempengaruhi secara positif signifikan dimensi konstruk Growth (Y24) sebesar 0,085 dengan nilai $\mathrm{p}=0,023$.

Terkait dengan ini, maka pay back Period (Y21), Return of Investement (Y23), dan Growth (Y24) menjadi dimensi konstruk/faktor yang serius diperhitungkan dalam memperbaiki Kinerja Industri Perikanan dan pengembangannya di Daerah Istimewa Yogyakarta. Sedangkan Rugi/Laba (Y22) karena dipengaruhi dengan tidak signifikan, maka tidak menjadi indikator penting yang diperhitungkan dalam proses operasi industri perikanan di Daerah Istimewa Yogyakarta. Hal ini mengindikasikan, bahwa faktor keuntungan yang menjadi ukuran kesejahteraan tidak terlalu diperhatikan oleh nelayan dalam menjalankan usahanya di Daerah Istimewa Yogyakarta.

Dari tiga dimensi konstruk yang berinteraksi signifikan terhadap Kinerja 
Industri Perikanan (LIP), pengaruh terhadap pay back Period (Y21) lebih dominan. Hal ini menunjukkan bahwa perputaran usaha sangat penting dalam kegiatan industri perikanan di Daerah Istimewa Yogyakarta, dimana kemampuan nelayan dalam pengembalian pinjaman, perputaran usaha pengolah ikan, dan musim tangkap selalu menjadi pertimbangan nelayan dan lainnya dalam menjalankan usaha perikanan. Bila melihat akar permasalahannya, dapat dipahami karena kegiatan industri perikanan tersebut umumnya dilakukan oleh nelayan dan pengolah ikan dengan modal kecil dan mikro yang akan terganggu kebutuhan rumah tangganya bila perputaran usaha mengalami masalah. Terkait dengan ini, maka dalam interaksi sederhananya, pengambilan kinerja perikanan tangkap di Daerah Istimewa Yogyakarta perlu mengedepankan kepentingan nelayan dan pengolah ikan modal kecil dan mikro daripada mendahulukan kepentingannya lainnya, misalnya kontribusi terhadap PAD. Hal ini sejalan dengan hasil analisis sebelumnya terkait pengaruh Rugi/Laba (Y22) terhadap Kinerja Industri Perikanan (KIP).

Hasil analisis SEM juga menunjukkan
Kinerja Industri Perikanan (KIP) berpengaruh positif signifikan terhadap Tujuan Pembangunan Perikanan (TPP) sebesar 0,057 dengan nilai $p=0,031$. Terkait dengan ini, maka Tujuan Pembangunan Perikanan (TPP) yang ditetapkan menjadi faktor serius mempengaruhi Kinerja Industri Perikanan yang dijalankan di Daerah Istimewa Yogyakarta. Untuk itu, maka pencapaian tujuan tersebut harus selalu menjadi fokus dalam setiap usaha perikanan tangkap yang ada. Bila belum terakomodir dengan baik, maka kinerja perlu ditingkatkan.

\section{Tujuan Pembangunan Perikanan (TPP)}

Dalam kaitan dengan dimensi konstruk (Tabel 5.), Tujuan Pembangunan Perikanan (TPP) dipengaruhi secara positif tidak siginifikan oleh Growth (Y31) sebesar 0,088 dengan nilai $p=0,109$, dipengaruhi secara positif signifikan oleh dimensi Sustainable (Y32) sebesar 0,037 dengan nilai $p=0,028$, dan dipengaruhi secara positif signifikan oleh Daya Saing (Y33) sebesar 1,000 dengan nilai $p=0,045$.

Oleh karena pengaruhnya yang signifikan, maka Sustainable (Y32) dan Daya Saing (Y33) menjadi dimensi konstruk yang

\section{Tabel 4. Koefisien Pengaruh dan Significance of Probability Dimensi Konstruk yang Berinteraksi dengan Konstruk Tujuan Pembangunan Perikanan (TPP).}

Table 4. Coefficient of Effect \& Signiface of Probability of Construct Dimension Interacted with Construct of Fisheries Development Goals.

\begin{tabular}{|c|c|c|c|c|}
\hline Konstruk /Construct & $\begin{array}{l}\text { Dimensi Konstruk } \\
\text { Indikator/ Endicator of } \\
\text { Construct Dimension }\end{array}$ & $\begin{array}{l}\text { Koefisien } \\
\text { Pengaruh/ } \\
\text { Coeficient of } \\
\text { Impact }\end{array}$ & $P$ & S/TS \\
\hline \multirow{3}{*}{$\begin{array}{l}\text { Tujuan Pembangunan } \\
\text { Perikanan (TPP)/ } \\
\text { Fisheries Development } \\
\text { Goals }\end{array}$} & $\begin{array}{l}\text { Pertumbuhan (Y31)/ } \\
\text { Growth }\end{array}$ & 0,088 & 0,109 & TS \\
\hline & $\begin{array}{l}\text { Keberlanjutan (Y32)/ } \\
\text { Sustainable }\end{array}$ & 0,037 & 0,028 & S \\
\hline & $\begin{array}{l}\text { Daya Saing }(\mathrm{Y} 33) / \\
\text { Competency }\end{array}$ & 1,000 & 0,045 & S \\
\hline
\end{tabular}

Sumber : Hasil Olahan SEM (2007)/Source :SEM Analysis (2007).

Keterangan/Remarks : $p=$ Nilai Significance of Probability/Significance of Probability.

$S=$ Pengaruh Signifikan/Significanthy Affected .

TS = Pengaruh tidak Signifikan/Unsignificanthy Affected. 


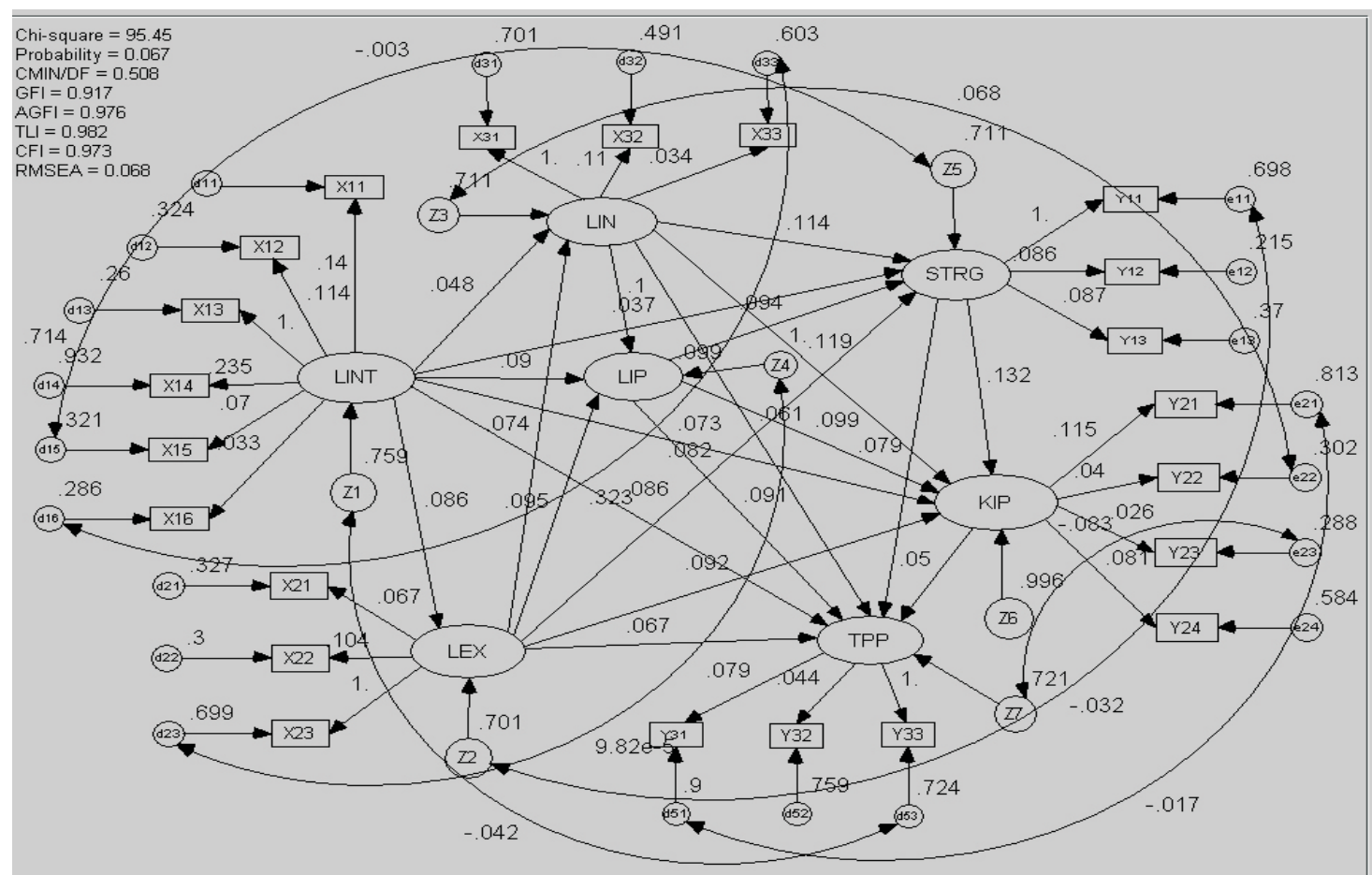

Gambar 2. Model Pengembangan Industri Perikanan dengan Interaksi Komplek Komponen Terkait.

Figure 2. Model of Fisheries Development Model with Complex Related Component Interaction.

berpotensi serius mempengaruhi Tujuan Pembangunan Perikanan. Sedangkan Growth (Y31) karena pengaruhnya yang tidak signifikan, maka tidak dianggap indikator penting yang diperhitungkan. Tidak signifikannya pengaruh Growth memberi indikasi bahwa Tujuan Pembangunan Perikanan di Daerah Istimewa Yogyakarta tidak terlalu dipusingkan oleh pertumbuhan usaha perikanan tangkap yang dilakukan nelayan.

Daya Saing (Y33) lebih dominan berinteraksi dan berpengaruh terhadap Tujuan Pembangunan Perikanan (TPP) dibandingan dengan Sustainable (Y32). Hal ini menunjukkan tujuan pembangunan di Daerah Istimewa Yogyakarta khususnya di bidang perikanan tangkap lebih memperhatikan bargening position dari produk yang dihasilkan oleh industri perikanan dibandingkan hal lainnya. Hal ini kemungkinan untuk memperkuat posisi produk yang dihasilkan dalam menembus pasar global yang lebih kompetitif.

Model Pengembangan Industri perikanan Dengan Interaksi Kompleks Dominan Dipengaruhi oleh Kondisi LINT, LEX,dan LIN

Model pengembangan ini merupakan modifikasi dari model sebelumnya, dimana interaksi dibuat lebih kompoleks dan dominan dipengaruhi oleh Lingkungan Internal (LINT), Lingkungan Eksternal (LEX), dan Lingkungan Industri (LIN). Ketiga konstruk ini dipilih sebagai faktor dominan karena pengembangan aktivitas industri di suatu kawasan biasanya tergantung dari pengembangan internal industri itu sendiri (peningkatan kapasitas industri), kondisi 
lingkungan eksternal yang kondusif, dan interaksi saling menopang dan membutuhkan diantara industri yang ada (industri pemasok, substitusi, pengguna produk, dan seterusnya).

Adapun interaksi baru dalam model ini adalah :

1. Lingkungan Internal (LINT) yang berinteraksi dengan : (a) Lingkungan Eksternal (LEX) positif signifikan dengan nilai koefisien pengaruh 0,086 dan probabilitas 0,002; (b) Lingkungan Industri (LIN) positif signifikan dengan nilai koefisien pengaruh 0,048 dan probabilitas 0,024; (c) Strategi Usaha (STRG) positif tidak signifikan dengan nilai koefisien pengaruh 0,037 dan probabilitas 0,276; (d) konstruk Kinerja Industri Perikanan (KIP) positif signifikan dengan nilai koefisien pengaruh 0,073 dan probabilitas 0,024; dan (e) Tujuan Pembangunan Perikanan (TPP) positif tidak signifikan dengan nilai koefisien pengaruh 0,086 dan probabilitas 0,129 .

2. Lingkungan Eksternal (LEX) yang berinteraksi dengan : (a) Lingkungan Industri (LIN) positif signifikan dengan nilai koefisien pengaruh 0,074 daan probabilitas 0,026; (b) Strategi Usaha (STRG) positif tidak signifikan dengan nilai koefisien pengaruh 0,082 daan probabilitas 0,117; (c) Kebijakan Industri perikanan (KIP) positif signifikan dengan nilai koefisien pengaruh 0,092 daan probabilitas 0,044; dan (d) Tujuan Pembangunan Perikanan (TPP) positif signifikan dengan nilai koefisien pengaruh 0,067 daan probabilitas 0,013 .

3. Konstruk Lingkungan Industri (LIN) yang berinteraksi dengan : (a) Strategi Usaha (STRG) positif tidak signifikan dengan nilai koefisien pengaruh 0,114 dan probabilitas 0,319; (b) Kebijakan Industri perikanan (KIP) positif signifikan dengan nilai koefisien pengaruh 0,119 daan probabilitas 0,048 ; (c) Tujuan Pembangunan Perikanan (TPP) positif signifikan dengan nilai koefisien pengaruh 0,061 daan probabilitas 0,017 .

4. Strategi Usaha (STRG) yang berinteraksi dengan Tujuan Pembangunan Perikanan (TPP) positif signifikan dengan nilai koefisien 0,079 dan probabilitas 0,012.

Dari tiga pengaruh signifikan Lingkungan Internal (LINT), pengaruhnya terhadap Lingkungan Eksternal (LEX) lebih dominan yang mengindikasikan kondisi dan aktivitas usaha perikanan tangkap yang ada di Daerah Istimewa Yogyakarta mempengaruhi kondisi lingkungan tempat usaha perikanan tangkap dilakukan, misalnya daya beli masyarakat, pola konsumsi masyarakat terhadop ikan laut, dan sebagainya. Sedangkan pengaruh Lingkungan Eksternal (LEX) terhadap Lingkungan Industri (LIN) yang bersifat positif signifikan mengindikasikan kondisi dan aktivitas masyarakat di Daerah Istimewa Yogyakarta mempengaruhi aktivitas industri lainnya di luar usaha perikanan tangkap. Pengaruh positif signifikan Strategi Usaha (STRG) terhadap Tujuan Pembangunan Perikanan (TPP) ini memberi indikasi bahwa strategi usaha berperan penting dalam pencapaian Tujuan Pembangunan Perikanan di Daerah Istimewa Yogyakarta.

\section{IV.KESIMPULAN DAN IMPLIKASI KEBIJAKAN}

\section{Kesimpulan}

Aspek manajemen merupakan aspek yang dipengaruhi signifikan paling dominan dalam interaksi di lingkungan internal usaha perikanan (koefisien pengaruh $=1,000$ dengan nilai $p=0,040)$. Hal ini mengindikasikan bahwa masalah manajemen (seperti kebijakan pendelegasian, promosi, miskomunikasi lintas bagian) paling rawan di internal industri perikanan, dan bila tidak diselesaikan dengan baik dapat secara serius menggangu kinerja usaha perikanan. Aspek sosial dipengaruhi signifikan paling dominan oleh Lingkungan Eksternal. Pengaruh yang tinggi ini dapat dikarenakan oleh sensitifnya 
masalah-masalah sosial (seperti masalah kesenjangan dalam penghasilan, kesempatan kerja, pendidikan, dan lainnya). Entry barrier dipengaruhi signifikan paling dominan oleh lingkungan industri (koefisien pengaruh $=1,000$ dengan nilai $p=0,045$ ). Hal ini menunjukkan bahwa keluar/masuk barang dari/ke usaha perikanan harus diperhatikan secara serius bila industri perikanan ingin tetap stabil dalam produksi. Aspek keuangan merupakan aspek paling sensitif dalam menentukan strategi pengembangan usaha perikanan tangkap. Hal ini karena usaha yang ada umumnya sangat lemah secara finansial sementara masyarakat nelayan sekitar sangat bergantung/membutuhkan pekerjaan dari pengembangan usaha perikanan tangkap tersebut. Pay back period dipengaruhi signifikan paling dominan oleh kinerja industri perikanan. Kemampuan nelayan dalam pengembalian pinjaman, perputaran usaha pengolah ikan, dan musim tangkap selalu menjadi pertimbangan nelayan dalam menjalankan usahanya. Aspek daya saing merupakan aspek yang paling diperhatikan dalam merumuskan tujuan pembangunan perikanan di Daerah Istimewa Yogyakarta (koefisien pengaruh $=1,000$ dengan nilai $p=$ 0,045).

Pada interaksi di lingkup yang lebih tinggi, Lingkungan Internal sangat dipengaruhi oleh Lingkungan Eksternal dan ini mengindikasikan bahwa maju-mundurnya aktivitas usaha perikanan tangkap sangat dipengaruhi oleh kondisi lingkungan tempat usaha perikanan tersebut dilakukan. Pengaruh Strategi Usaha (STRG) terhadap Tujuan Pembangunan Perikanan (TPP) juga positif signifikan dan ini memberi indikasi bahwa strategi usaha yang ada berperan serius dalam pencapaian Tujuan Pembangunan Perikanan di Daerah Istimewa Yogyakarta.

\section{Implikasi Kebijakan}

Interaksi komponen yang bersifat signifikan dan prioritas yang dihasilkan dari penelitian ini dapat digunakan sebagai dasar pengembangan usaha perikanan tangkap melalui pembentukan Unit Bisnis Prikanan Terpadu (UBPT). Hal ini direalisasikan dengan tahapan sebagai berikut: (a) penyusunan regulator untuk lingkungan bisnis kondusif, yang dapat menjadi dasar pelaksanaan UBPT dengan berorentasi pada aspek manajemen, sosial, keuangan, daya saing, pay back period dan entry barrier; (b) pada saat UBPT dijalankan, aspek teknologi, ekonomi, pemasaran, growth dan sustainable langsung dibenahi sehingga usaha perikanan tangkap mempunyai posisi daya saing dalam bisnis perikanan tangkap kuat.

\section{DAFTAR PUSTAKA}

Departemen Kelautan dan Perikanan (DKP). 2003. Pedoman Umum Pemberdayaan Ekonomi Masyarakat Pesisir (PEMP).

Dinas Perikanan dan Kelautan DIY. 2004. Rencana Strategis 2004 - 2008. Yogyakarta.

Departemen Kelautan dan Perikanan. 2005. Rencana Strategis Pembengunan Kelautan dan Perikanan tahun 20052009. Jakarta. 2005.

Ferdinand, A. 2002. Structural Equation Modelling dalam Penelitian Manajemen. BP UNDIP. Semarang.

Gunawan, S. 1996 Membangun Perekonomian Rakyat. Ekonomi Pembangunan. IDEA dan Pustaka Pelajar. Yogyakarta.

Porter L. 1980. Competitif Strategi. A Division of Mac Millon Publishing Co, Inc. New York

Solimun,MS. 2002. Sructur Equation Modelling (SEM) Lisrel dan Amos (Aplikasi di Manajemen, Ekonomi Pembangunan, Psikologi, Sosial, Kedokteran dan Agrokomplek). Fakultas MIPA Universitas Brawijaya Malang. 